\title{
Involving young people through co-production and widening participation approaches: Reflections from school-based engagement
}

\author{
Sanchika Campbell* - King's College London, UK \\ Billy Gazard - King's College London, UK \\ Charlotte Woodhead - University College London, UK \\ Lisa Harber-Aschan - Karolinska Institutet, Sweden \\ Stephanie Beards - National Children's Bureau and King's College London, UK \\ Jonathan Harber-Aschan, Molly Gazzard, Esma Yaman and Angela Murugesu - \\ Christ the King Sixth-Form College, UK \\ Stephani L. Hatch - King's College London, UK
}

\begin{abstract}
Co-production techniques that involve student voice have been shown to empower young people and shape their learning experiences, while widening participation approaches can improve students' educational aspirations. However, there is limited literature on the impact that a combination of co-production and widening participation approaches might have on students' learning, aspirations and self-esteem in the UK. The Research Methods in School Education (RISE) educational course aims to: (1) create a collaborative educational activity through co-production, giving young people an opportunity to voice their opinions; (2) raise awareness of community health issues; and (3) increase access to higher education. This paper describes and evaluates co-producing the RISE educational course with students and teachers from a sixth-form college in south-east London, drawing on students' voice, and on insights from teachers and researchers. We also assess the contribution of the course to improved awareness of community health issues, students' educational or career aspirations, and self-esteem.
\end{abstract}

Keywords: young people; co-production; community health; widening participation; health inequalities; public engagement

Key messages

- The process of co-production in the Research Methods in School Education (RISE) pilot contributed to the design and delivery of this pilot course. Collaboration and equitable engagement between stakeholders were key to the course's positive impact. Practical issues around communication, course outline and delivery need to be addressed to improve future courses, and maintain the sustainability of the initiative.

- The course had a positive impact on students' awareness of community health issues. Offering students an opportunity to engage in relevant research projects by incorporating a youth participatory action research approach could empower young people further.

- RISE had an impact on widening participation by boosting students' aspirations and confidence. Adapting the course for earlier stages of secondary school education could better empower students from disadvantaged backgrounds. 


\section{Background}

Young people's everyday school experiences provide a wealth of knowledge to enable them to co-produce effective learning experiences. Drawing on the student voice has been emergent in educational reform over the last couple of decades, and involves gaining unique perspectives from young people on learning, teaching and schooling (Cook-Sather, 2006). To positively involve student voice requires listening to and acting on students' perspectives and affording them opportunities to engage in shaping their education (Cook-Sather, 2002). However, in wider research, the voice and ideas of students are often missing in dialogues around enhancing learning experiences.

Co-production refers to an equitable and collaborative partnership between those involved (Banks et al., 2013). The theory of co-production grew in the late 1970s in the USA, focusing on collaboration between service providers and clients to improve public services (Ostrom, 1996). It has since been used to describe individuals engaged in contributing to, or collaborating with, the production of services they use (ibid.). The five key elements of co-production are: (1) clients and users of services being active agents in the process; (2) relationships are equal and contributions are valued; (3) the partnership is reciprocal and has mutual benefits; (4) participation informs design and delivery of services; and (5) the participation of users is encouraged and supported by organizations (Heaton et al., 2016). For example, an Australian school-based study incorporated student voice to explore how well-being is perceived and facilitated. Using a co-production approach, they demonstrated students' capacity to share their experiences in a way that could improve school environments and relationships to promote student well-being (Simmons et al., 2015). However, literature on the impact of school-based co-production educational initiatives on students' awareness of local issues, their aspirations and their self-esteem is limited in a UK educational context.

Another way to influence educational aspirations is through widening participation activities. Widening participation in the UK aims to increase the representation of economically disadvantaged and ethnic minority students in higher education (Vignoles and Murray, 2016), and has the potential to improve educational aspirations in young people from less privileged backgrounds. The widening participation agenda, a key policy initiative for the Labour government in the UK (1997-2010), which has continued through successive governments, involved bursaries to incentivize students from deprived backgrounds into higher education (Harrison et al., 2018). However, bursaries as a policy tool may be insufficient to progress the widening participation agenda (Harrison and Hatt, 2012), and from a social justice perspective, widening participation activities ought to increase students' aspirations, awareness, and the perceived value of higher education (Vignoles and Murray, 2016). A study aiming to improve transition between secondary school and higher education in the Netherlands demonstrated how close cooperation between secondary schools and universities through a pre-university programme (U-Talent) successfully engaged and motivated students (Michels and Eijkelhof, 2018). The study involved interaction between secondary school students and university researchers to improve students' science education and academic success, as well as promoting the professional development of science teachers and public engagement with schools. It showed how collaboration enabled universities to support secondary-school-level students to better engage with science subjects, as well as allowing researchers to disseminate scientific research and increase student aspirations.

As widening participation activities aim to positively influence the educational aspirations of young people from marginalized backgrounds, we took a widening participation approach to co-produce and develop the Research Methods in Schools 
Education (RISE) course. We decided to work with students in the final years of secondary school (AS/A-level students), in order to positively influence their academic aspirations, given their potential transition to university following $A$ levels. The researchers involved in RISE were engaged with mental health research at the Institute of Psychiatry, Psychology and Neuroscience (IoPPN), particularly around addressing health inequalities. All RISE researchers are members of the Health Inequalities Research Network (HERON), an international public engagement network with a vision of collaborative research in the community, aimed at bringing together community members, charities, public health researchers and health practitioners to tackle health inequalities. As part of HERON, the RISE pilot sought to increase students' educational aspirations and self-esteem through a course that aimed to: (1) create a collaborative educational activity through co-production, giving young people an opportunity to voice their opinions; (2) raise awareness of community health issues; and (3) increase access to higher education environments.

In this paper, we describe and evaluate the process of co-producing the RISE course. The paper will begin with an overview of the course, including the setting, process timeline, recruitment, workshop and final event details, and data collection in relation to co-production and evaluation of the pilot. Following this, we will share reflections on co-production from the perspectives of students, teachers and RISE researchers. We also aim to assess how RISE contributed towards awareness of community health issues by discussing how students' awareness evolved through the workshops, their final presentation topics and their feedback around community health awareness. Finally, we aim to describe the influence of RISE on young people's career aspirations and self-esteem. We then discuss key learning points around the three aims, and future directions for RISE.

\section{Setting up the RISE course}

The course aimed to introduce the topic of research methods in an engaging and interactive way. In practice, this involved using local real-life health data and facilitating discussions of students' lived social experiences to help them think critically about social problems affecting them and their communities. In turn, we hoped to motivate students' interest in health research and to increase their higher education aspirations.

The RISE course was initially conceptualized during a meeting between a group of researchers based at the IOPPN, and a curriculum director from a local southeast London college. Following this conversation, the RISE team was founded, and included five researchers, three teachers (Head of Centre, the Curriculum Director and an A-level sociology/psychology teacher from the sixth-form college) and the founder of HERON. The process timeline can be seen in Box 1.

Activities were based across both the sixth-form college and university locations to optimize participation and promote aspiration through developing familiarity with a university setting. In the UK, a sixth-form college provides the setting for secondary school education of students usually aged 16 to 19 . Students were from a comprehensive (non-selective state school) sixth-form college in south-east London, situated in one of the most socially deprived areas in England. The college serves a diverse and multicultural community, where over half of its students are considered learners from disadvantaged backgrounds (around 23 per cent of students qualify for free school meals and bursary financial support (Christ the King College, n.d.)), and 76 per cent are from ethnic minority groups (Ofsted, 2010). Students face a range of barriers to participation in further and higher education, and the Curriculum Director shared that many students are the first in their family to consider university as a viable option. 
Box 1: Process timeline

The timeline of the RISE project is set out below, with overlapping durations throughout the process.

Funding and ethics (June-September 2016)

> June 2016: Submitted funding application to King's College London (KCL) Widening Participation team.

> September 2016: Ethics application to evaluate and co-produce RISE as an educational course submitted. RISE researchers obtain Disclosure and Barring Service (DBS) clearance as a legal requirement to protect the safety of students.

Planning and developing RISE (August-November 2016)

August 2016: First meeting to formally discuss RISE with teachers and researchers from August 2016.

Implementation and co-production (October 2016-March 2017)

> October 2016: Students enrol into co-production element of RISE; all students consented to becoming co-producers of the RISE course. Students' research interests, workshop participation, feedback, focus group involvement and engagement in co-writing this article contributed to the co-production and evaluation of RISE.

\section{Dissemination (February 2017 to date)}

> February 2017: Students presented group research ideas to an academic audience and expert panel of judges at a final event at the loPPN, KCL.

> July 2017: RISE researchers disseminated the project's findings at an invited symposium session ('Engaged learning' conference, Sheffield University).

$>$ 2017: Three students and the Curriculum Director contributed to this publication as co-authors.

The programme was aimed at psychology and sociology A-level students, but was open to all sixth-form students. Teachers advertised the RISE course in class and via flyers and email circulars. Interested students were directed to an online application form. Students were asked to indicate their reasons for applying and their future educational/career aspirations, and to identify what they thought was the biggest health issue in their local area and how they would change this. All 19 applicants were accepted onto the course. RISE team members then arranged an information meeting with students at the college site to explain the opportunity to co-produce a piece of research with $\mathrm{KCL}$, which involved getting their views and feedback on the course, its content and structure. The co-production process would examine the success of the RISE pilot course and its adaptability as an educational tool for future students. The RISE team emphasized that the co-production aspect was optional and would not affect the students' participation in the workshops. Students were given an information sheet and one week to decide whether they would like to take part. All students consented to participate in co-producing RISE.

As part of a widening participation opportunity, all students on the course were offered one day of work experience at the loPPN, which took place after the course, during the summer holidays. Out of ten students who signed up, five attended the work experience day. 
A flowchart summarizing the RISE course is provided in Figure 1. Through a series of workshops, students learnt about health inequalities, different study designs and basic quantitative and qualitative methods, using examples of local research data collected for the South East London Community Health (SELCoH) study (Hatch et al., 2011 , 2016). Students then applied what they learnt to the design of their own research project proposals based on health problems that they had identified as important in their communities. RISE team members facilitated the workshops and mentored student groups. Mentoring included supporting students to think critically about their research questions and methods, providing feedback on presentations and meeting with allocated groups before the final event.

\section{Figure 1: Flowchart of the RISE course}

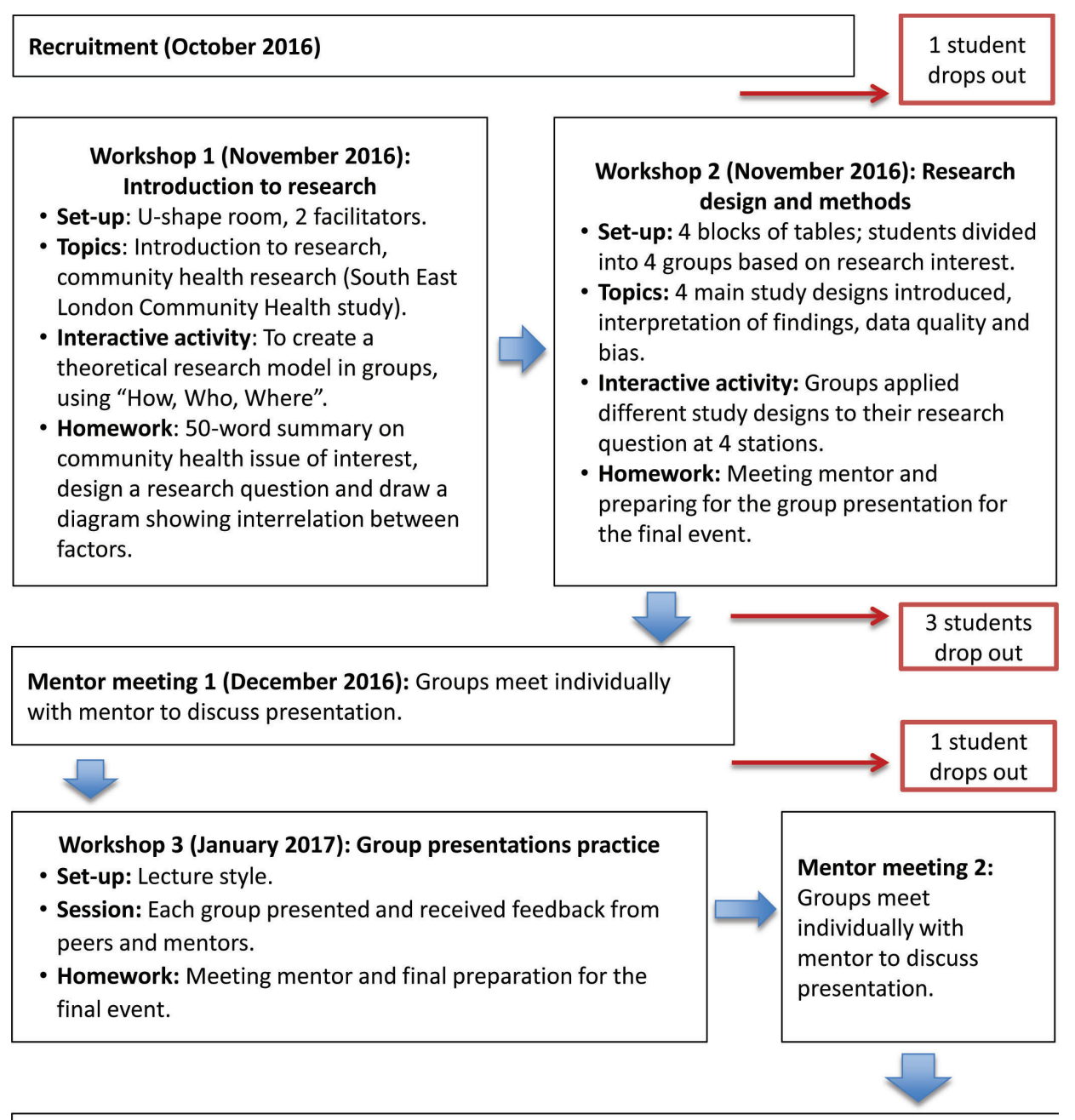

Final event (February 2017): Presentation at King's College London

- Set-up: Lecture style.

- 14 students (4 groups) presented to an academic panel \& audience; 10 minutes per group presentation.

- Winners awarded vouchers; best group and best individual presenter category.

The final event was held in a seminar setting at the IoPPN. Students presented their work to an academic audience and expert panel of researchers at KCL. To promote diversity and inclusion, we invited a panel that was ethnically diverse, gender balanced and represented various academic levels. 


\section{Data collection and analysis}

Through the process of co-production, we shared an open dialogue with students and teachers to shape RISE as an effective educational tool. Throughout the course, students also completed self-report questionnaires after each workshop, allowing us to gauge their immediate impressions and continuously improve the course as it went on. Before the first workshop and after the final event, students were asked to complete questionnaires to assess any change in their educational aspirations, career aspirations (for example, 'what is your chosen educational, career path or job role?') and community engagement (for example, 'have you ever taken any action to tackle a social problem; e.g. volunteered with a community organization or attended a protest?'). The questionnaires also captured key sociodemographic information. The co-production process is shown in Figure 2.

\section{Figure 2: Co-production phases of the RISE course}

\section{Phase 1: Recruitment}

\begin{tabular}{|c|c|}
\hline $\begin{array}{c}\text { Application form: Using an open-ended questionnaire } \\
\text { in the initial application form, we asked students about } \\
\text { their expectations, aspirations and outcomes from } \\
\text { their participation. }\end{array}$ & $\begin{array}{c}\text { All students } \\
\text { consented to } \\
\text { participate in co- } \\
\text { producing RISE. }\end{array}$ \\
\hline
\end{tabular}

Phase 2: Workshops and final event

Feedback was requested in self-report questionnaires at the end of each workshop, and after the final event. We used feedback to continuously gauge students' perspectives and improve the course as we went along.

\begin{tabular}{|c|c|c|}
\hline $\begin{array}{c}\text { Workshop 1 } \\
\text { feedback }\end{array}$ & $\begin{array}{c}\text { Workshop 2 } \\
\text { feedback }\end{array}$ & $\begin{array}{c}\text { Workshop 3 } \\
\text { feedback }\end{array}$ \\
\hline
\end{tabular}

Final event (presentation at King's College London) feedback

\section{Phase 3: Focus group (at the end of the course)}

Students were invited to take part in a focus group at the end of the course, lasting one hour. Ten students took part. Students' views were elicited to inform improvements to the pilot course and gauge what impact it had on their learning, confidence and future aspirations.

All the feedback from the focus group and self-reported questionnaires was collated and used to improve subsequent RISE workshops.

\section{Phase 4: Student voice - reflections on RISE}

Three students who expressed interest in co-authoring this RISE publication provided their reflections on the course and co-production. The Curriculum Director also shared his reflections and experience.

\section{Phase 5: Dissemination}

In continuity of the co-production process, students were invited to engage in the dissemination of this study:

- Three students are co-authors on this RISE paper.

- One student co-presented on the RISE course at an academic seminar at King's College London. 
All data were transcribed, and anonymized on transcription. All qualitative data were entered into NVivo 10 for data management. Data were thematically coded. Thematic analysis is a search for patterns (themes) in qualitative data salient to the phenomenon under study (Fereday and Muir-Cochrane, 2006). Following familiarization, initial descriptive codes were applied to short sentences or phrases. These codes were then refined after discussion between facilitators of the RISE course, and themes were developed both deductively and inductively. These themes informed understanding of participant experience and attitudes towards the course, and suggestions for future improvement.

The research team obtained ethical approval from the King's College London Psychiatry, Nursing and Midwifery Research Ethics Committee (reference LRS-16/173733) for students to take part in the co-production of the study.

\section{Results: Student reflections and insights from teachers and researchers}

Of 19 applicants who started, 14 students (74 per cent) completed the course. One student dropped out before the course started; three students left after the first workshop, and one after the first mentor meeting. Reasons for drop-out included changing their mind about the course (three students), personal reasons (one student) and leaving the college (one student). Teacher feedback indicated only two students from vocational courses applied; one of these students dropped out due to lack of confidence in their ability and for socio-economic reasons.

A key feature of co-producing RISE was to give voice to the students involved - not only on local community health issues that mattered to them, but also to shape RISE as an effective learning experience for young people in the future.

Co-production was integrated throughout the RISE process, and was received positively by students. Students engaged well with co-production and participation in the RISE course. This is reflected by the low drop-out rate, the consistent engagement and contributions from students throughout the process, and their motivation to see the course through.

The researcher-student relationship was fundamental to building a collaborative and equitable partnership in co-producing RISE. We fostered this collaboration by encouraging and respecting a critical student voice from the outset and throughout the course, and reinforcing the fact that students would be co-producers of the course. As researchers, we felt we were able to generate a reciprocal transfer of knowledge, skills and insight into the complex set of determinants that perpetuate local health inequalities. By drawing on students' lived experiences and developing their critical consciousness of community health problems, we also learnt about which local health disparities were of greatest concern to young people. As part of co-production, participation helped to validate their experiences and facilitated collaborative learning. We were able to show students that the findings generated by research can support those advocating social change. For example, we shared publications/findings arising from the SELCoH study (Hatch et al., 2011), which highlighted the prevalence of mental health problems in the local area, as well as persistent health inequalities. Students were taught that these findings can be used to help health service providers plan and improve local services more efficiently, and by designing their own research studies, students shared which issues were important to them, and whether they discussed their topics with family/friends. 
From student feedback and student reflections in this paper, the mentoring process arose as an important contributor to building confidence and developing key skills relevant to their academic studies. In fact, students stated that they would have liked more mentoring sessions throughout the whole course, with extra guidance through the planning stages and in the lead-up to the final event. One student requested that mentors share more about their experiences with research. Students brought up mentors' approachability, their allocated expertise for each group's research question and their feedback in shaping the presentations for the final event. A key challenge that mentors experienced was with communicating with students via emails because of infrequent responses.

Teachers had an essential role in the whole RISE process, and building relationships with the teachers was a key facilitator to advertising the RISE course, supporting students to participate and acting as intermediate communicators between researchers and students. Further, input from the teachers was crucial in designing the course and materials in terms of content, identifying ways to best engage students and making the learning more meaningful to their existing studies.

All students $(n=14)$ felt that the course content was at the right level, neither too difficult nor too easy; 13 students felt that the workshops prepared them well to do the set work between sessions. Students particularly enjoyed the interactive activities, debates and discussions in the workshops.

The suggested improvements to the workshops centred heavily on increasing the activities in the workshops and making them even more interactive to improve engagement. Other suggestions included frequently alternating the speakers facilitating the workshop, having shorter workshops and spending more time explaining the different research study designs. Moreover, many students preferred working in smaller groups and then engaging in wider discussions. Overall, students were very satisfied with the course, and 10 out of 14 students said that they would recommend the course to their friends.

All students who completed the course reported enjoying the final event; in particular, the university venue, expert panel and audience, and the structure of the event. In the focus group $(n=10)$, students shared a sense of accomplishment after presenting - from pride in their group's presentation, the sense of reward from the effort they had put in, and the experience of presenting. Generally, the competitive element was well-received. For example, in retrospective feedback, one student said: 'It was nice to see the elements of competition but still so much consideration and support between peers and mentors.'

Although we outlined the course structure in students' course folders and at the first workshop, students wanted more information and clarity on workshop dates, the final event and what the course entailed. This suggests that we need to make the presentation of this information clearer from the outset and reiterate it throughout the course.

\section{Impact on students}

Below we reflect on whether RISE contributed to students' awareness of, and engagement with, community health issues. Following this, we present the influence of RISE on young people's career aspirations and self-esteem, and how this connects to the widening participation agenda. 


\section{Awareness of community health issues}

A key part of the course was to encourage young people to think critically about social problems that affect them and their communities. Students' motivation in doing so was evident in their initial applications for the course. In their initial application, one student said: 'I feel that the RISE project would be a fantastic opportunity for me to use my knowledge and skills, to investigate health issues in my local area that people struggle to deal with on a daily basis.'

Students' perspectives on the root causes of poor community health developed throughout the process. During group discussions, students' ideas initially focused on individual health behaviours as the main cause for health inequalities. Throughout the course, students developed a more nuanced understanding, incorporating broader sociocultural, structural and community-level influences. This was demonstrated by the group presentations at the final event showcasing a deeper understanding of causes of health inequalities beyond individual behaviour. Presentations included exploration of risk factors such as substance abuse, exposure to violence, discrimination, eating habits and academic pressure. Students were initially grouped based on their interests in community health issues. Within their groups, they agreed on the topic for their final presentation. Students explored underlying causes and differences in exposure to risk factors and potential health-related impacts. In particular, there was a desire to tackle issues they felt affected the mental health of young people.

Out of 14 students, 13 said that the course had inspired them to understand more about their own community's health, and for 5 students, the course had inspired them to take action to tackle a social problem related to health, including raising awareness and campaigning. Five students had spoken to others outside the course about their presentation topics. Teachers supported these findings, commenting on the knowledge that they felt students had gained:

On a broader level, the students gained an insight into the myriad of health problems within South-East London ... The fact that they were able to then consider the impact of their research also encouraged the students to further develop their sense of civic responsibility. (Curriculum Director, retrospective feedback)

Out of 13 students, 10 expressed that they felt motivated to carry out a research project in which they could implement their research designs, if the opportunity to do so was available in a summer course format.

\section{Young people's career aspirations and self-esteem}

Out of 14 students, 9 students felt that RISE had influenced their career aspirations. During the focus group, out of 10 students, many felt that taking part in the course confirmed that they wanted to embark on a career in a health-related discipline such as psychology, paediatrics and other medical sectors. The theme of wanting to help others and working with vulnerable populations in the future was echoed by most students during the RISE course.

Reflections from the Curriculum Director underscored the challenge for students of engaging with academic research:

The task they embarked on was challenging and in an environment, that was far outside their comfort zone.... These students performed well and 
some have gone on to take a more active role within the student leadership within the college. (Curriculum Director, retrospective feedback)

Students' perceptions of higher education environments seemed to be influenced by their familiarity with researchers from $\mathrm{KCL}$, making entering higher education institutions less daunting. As the Curriculum Director explained: 'Moreover, the experience of working with approachable and patient academics at King's College London demonstrated to them that academic environments are not an alien place in which these students cannot become a part of.'

Four students in the focus group who had not previously thought of research as a career option now considered it as a possibility. One student later went on to apply for and win a Youth Award in Health Economics at $\mathrm{KCL}$, which provides two days of work experience in a research setting and twelve months of mentoring from a researcher at the university.

In terms of widening participation, students' reflections in this paper and focus group discussions indicated that the course had influenced some students to go to university and inspired their subject choice:

Before completing the [RISE] project, I had no idea about how it would benefit me, but at some point, within the course of the project I came to the realisation that conducting research is something I enjoyed and would like to consider collaborating it with my current plans for my future further education and career. (Student, retrospective feedback)

Such observations support the goals of the widening participation scheme, which aims to improve the educational aspirations of young people and encourage them into higher education. Following the course, five students attended the work experience opportunity and three students engaged in dissemination of our findings.

Throughout the RISE process, the growth in students' academic and personal confidence was an important course outcome. Confidence was a strong qualitative theme in student feedback throughout the RISE process. Further, the growth in students' self-esteem was noticeable from the perspective of both teachers and researchers. Prior to the course, confidence building and development of public speaking skills was identified as an aim by some students in their reasons for participating in RISE, and following the course, many students felt this had been accomplished. For example, one said it 'helped a lot with public speaking, we researched it ourselves. It was not someone else's work.'

By the end of the course, all students $(n=14)$ indicated via feedback forms that the course had increased their academic confidence in understanding research and speaking about topics important to them:

As well as gaining a deeper understanding, my gained knowledge from the RISE project has been something that I have been able to further apply to my studies, helping me with exam preparation and just making the understanding of my subjects much easier. (Student, retrospective feedback)

Teachers also discussed how students had gained transferable skills from the course, particularly in preparing to present in a university environment. The Curriculum Director shared that developing students' social skills and verbal literacy to articulate 
themselves in academic/professional environments were major achievements of the RISE pilot.

\section{Discussion and key learning points}

RISE was found to have broader implications in terms of boosting confidence and empowering young people through participatory engagement. Such findings around student empowerment align well with co-production findings (Simmons et al., 2015) and widening-participation-related approaches (Michels and Eijkelhof, 2018), showing the potential of the course to encourage young people to continue with further education, and to some extent inspire their choice of degree course. Our reflections on the RISE pilot raised key learning points around the three main aims of the paper.

\section{Co-production}

Co-production and student voice in educational settings can be an opportunity to become more involved and act 'with' students in reflecting on health and social inequalities (Brydon-Miller and Maguire, 2009). Engaging with students as co-producers of the course, seeking their voice on the learning experience and valuing their input contributed to the acceptability of co-production. Throughout the process, we felt that we incorporated the five main features of co-production (Heaton et al., 2016). For example, students were active agents through their ongoing participation and involvement in dissemination, the partnership between students and researchers was reciprocal and respectful, and we adapted the course based on students' views.

Student co-authors' role in writing this article included sharing their reflections and commenting on the draft publication and subsequent revisions. As such, while highlighting the student voice was an essential part of this paper, it was important for us that student co-authors were involved in the publication process, as both an opportunity to sustain their voice and as a learning experience.

Effective collaboration between students, teachers and researchers was integral to the co-production approach. Students' feedback was vital to shaping RISE as an effective learning experience, and was incorporated into the design and delivery of future courses. Researchers had an essential role in engaging students in learning about research methods and effectively mentoring them. Teachers' input ensured that we pitched the course at the right level to keep students engaged, and their perspectives were important in evaluating the impact of the course on students. Teachers' involvement in the recruitment process increased our capacity to widen participation, and ensured a low level of drop-out. They also acted as intermediate communicators. The crucial role of teachers in the school-university collaboration is also recognized in Michels and Eijkelhof's (2018) study of the U-Talent programme.

A key learning point in this process was on practical issues around communication with this cohort. One challenge around communication was that students felt that details of the course and the final event were inadequately communicated. Future courses should clearly outline this at each workshop. Second, we used emails as the main method of contacting students; however, we found this was ineffective due to students' lack of response. Surprisingly, students expressed that emails worked well for them, indicating perhaps that they were satisfied with the content and frequency of information that researchers sent through emails. Future RISE courses could explore 
and develop shared expectations for communication/response and consider using social media to improve communication.

Students' commitment to the course despite their already busy academic schedules indicates that the RISE model could be used in future school-based work. Teachers were integral in motivating students to participate, and the mentoring sessions sustained this motivation. We have demonstrated that co-production on the topic of health inequalities works well, given the relevance of using local data to teach research methods. It should therefore also be possible to adapt the research methods course to other topics around social justice.

As part of the research and community engagement work within HERON, we have maintained contact with some students from the RISE pilot study. However, a limitation of the co-production process is that one-off data collection through this pilot is insufficient to reflect on the impact of RISE on students over time, and future work in this area should promote ongoing engagement with young people and continue to promote reciprocity.

\section{Students' awareness of community health issues}

Through co-production, the pilot also stimulated consciousness around community health issues. The group presentations at the final event captured the student voice by showcasing research questions considering risk factors, health-related impacts and population groups that students were concerned about. The presentations were diverse, but the focus of all groups on tackling issues related to the mental health of young people was evident.

Students were taught more about what research entails and the potential research has for examining issues around social justice. As researchers, we were impressed with the students' ability to process local health data and design their own research projects, and their expressed desire to address local health and social inequalities linked to mental health.

A limitation of RISE is that we were unable to offer students the chance to carry out research due to factors such as funding, the specific time allocated to the course and time requirements for the research process (for example, ethics applications, recruitment). Youth Participatory Action Research (YPAR) approaches view young people as assets in promoting positive change in their own lives, in local communities and across relevant social institutions such as education, health and criminal justice (Fox et al., 2010). Through YPAR projects, young people identify local issues important to them and their community, and use research to identify opportunities to enact social change (Berg Powers and Allaman, 2013). The focus of RISE workshops on research enquiry, problem-solving concepts via research design, and constructing knowledge that immediately connected to students' lives, support some of the principles of YPAR (Rodríguez and Brown, 2009). As a key learning point, the RISE team are interested in offering students the opportunity to complete small research projects in the future, using a YPAR approach. This could impact on students' sense of civic participation (Cammarota and Fine, 2008; Cahill et al., 2008); consolidate their understanding of course content ('learning by doing') (Kilburn et al., 2014); and challenge their cognitive assumptions driving their research questions and anticipated findings (Kirshner et al., 2011). 


\section{Impact on students' future aspirations and self-esteem}

RISE had an impact on widening participation and met the aim of increasing awareness of community health, boosting students' future aspirations and confidence. On the whole, student engagement was positive, and RISE was able to meet some widening participation goals through collaboration between the school and the university. However, a future priority should be revising the application process, encouraging students with mixed academic abilities to participate in RISE and outreach to less motivated students.

A study found that among students from marginalized backgrounds, attainment at secondary school (ages 11-16) was better at explaining poor participation in higher education (university/degree level) than difficulties at sixth-form (ages 16-19), suggesting a need for earlier engagement (Chowdry et al., 2013). It is important to explore students' expectations of higher education, which are influenced by socioeconomic factors (Vignoles and Murray, 2016). To address these potential barriers, future RISE courses could be adapted for secondary school level and include discussions on students' expectations of higher education, university financial costs and how universities can support students from lower socio-economic backgrounds (bursaries, for example; Church and Kerrigan, 2011). Adopting a 'widening capability' approach focused on building students' potential and capability in earlier stages of secondary school education, as part of widening participation, could further empower young people from disadvantaged backgrounds and their aspirations (Hannon et al., 2017). However, we need to consider the structural barriers that students from low socio-economic backgrounds face, and be cautious of promoting 'cruel optimism' in terms of high student aspirations, unmatched to their possibility of attaining them (Berlant, 2006).

In terms of sustainability and maintaining positive outcomes, while we observed some important short-term benefits of RISE, the long-term impact of the project still needs to be assessed (Vignoles and Murray, 2016). The growth in students' academic and personal confidence was an important outcome of the course, but sustainability is essential. The RISE team are interested in following up students' aspirations, academic/career directions and civic participation, over the longer term. Maintaining students' connection with the university, and offering research project opportunities, may help to sustain personal and academic confidence and ambition, and present a way of measuring this over time. Long-term academic impact could also be assessed by comparing students' final grades at A level to their peers, using school examination data, university applications and acceptance rates.

\section{Future directions}

The RISE course has already been reshaped into different formats to accommodate the needs and timetables of schools. These include pilots of a week-long summer school version, where A-level students from widening participation backgrounds were invited to University College London, and a briefer course over two workshops with Year 10 and 12 psychology students in a local secondary school. To maximize the impact of this educational programme, we have also developed a training package that allows us to train new RISE facilitators to deliver the workshops.

RISE was re-funded by the Widening Participation Team of KCL in 2017 to run the RISE course over ten weeks as part of an enrichment programme in students' curriculum at the same sixth-form college. We incorporated learnings from the original 
pilot to improve the course, including shorter, more interactive sessions, and clearer information on the course. To increase uptake from local schools, collaborations are in progress between the RISE team and a large school-based research study called Resilience, Ethnicity, and AdolesCent Mental Health (REACH) (www.thereachstudy. com). Future plans also include discussions around a summer school course format to facilitate students conducting their research. Students involved in RISE have received opportunities to engage in various research activities as part of the Health Inequalities Research Network (HERON; https://heronnetwork.com) at KCL.

\section{Conclusion}

The pilot showed the potential for widening participation and co-production approaches to generate effective partnerships between schools and academic institutions. Through co-production, we were able to explore students' perceptions throughout the process and adapt the RISE course as a flexible educational tool for public engagement purposes by researchers who want to engage with young people. As a result, we felt learning and participation were meaningful and aligned with students' experiences of community health issues. The collaborative approach encouraged a critical student voice, essential to improving the course, and, to an extent, demonstrated that co-production can be used to facilitate awareness, change and social justice. In terms of widening participation, the course had a positive impact on students' future educational and career aspirations, and demonstrates the importance of community engagement between academic institutions and educational establishments. Such approaches could also serve as a basis for YPAR projects around social issues within the local community and community organizations.

\section{Acknowledgements}

We would like to thank the Widening Participation Team at King's College London for funding this project. This work was supported by the Wellcome Trust [203380/Z/16/Z].

We would like to extend our gratitude to all those who collaborated to produce the RISE course, particularly the teachers at the sixth-form college, and researchers from the Health Inequalities Research Network (HERON) and Resilience, Ethnicity, and AdolesCent Mental Health (REACH) network, whose collaboration made this project possible. Finally, a very big thank you to the students involved in the RISE project for their engagement, contributions and enthusiasm.

\section{Notes on the contributors}

Sanchika Campbell is a research worker for the Integrating Mental \& Physical Healthcare: Research, Training \& Services (IMPARTS) project at the Institute of Psychiatry, Psychology and Neuroscience, $\mathrm{KCL}$, and a member of the Health Inequalities Research Network (HERON). Her research interests include addressing health and social inequalities through community engagement approaches.

Billy Gazard is a postdoctoral research associate at the Institute of Psychiatry, Psychology and Neuroscience, and a co-coordinator of the Health Inequalities Research Network (HERON). His research interests include health inequalities and public mental health. 
Charlotte Woodhead is a postdoctoral research associate at University College London, and a member of the Health Inequalities Research Network (HERON). Her research interests lie in applied research into public mental health, health inequalities, and mental-physical co-morbidities.

Lisa Harber-Aschan is a postdoctoral researcher at the Department of Public Health Sciences at Karolinska Institutet, Sweden, a visiting researcher at the Institute of Psychiatry, Psychology and Neuroscience, KCL, and a member of the Health Inequalities Research Network (HERON). Her research interests include community health, health inequalities and mental-physical co-morbidity.

Stephanie Beards is a senior researcher in the Research and Policy Team at the National Children's Bureau (NCB), a visiting postdoctoral research associate in the Society and Mental Health Research Group at the Institute of Psychiatry, Psychology and Neuroscience, and a member of the Health Inequalities Research Network (HERON). Prior to joining NCB, she coordinated the REACH study - an accelerated cohort study of youth mental health, and led on the public engagement aspects of the project. Stephanie is a keen advocate for participatory approaches and facilitating young people's involvement to improve research outcomes and policy influencing.

Jonathan Harber-Aschan is a curriculum director, history and politics teacher at Christ the King Sixth-Form College. Jonathan has been involved in extra-curricular projects aimed at developing a range of academic skills and instilling within the student population a broader understanding of local and national socio-economic and political developments. He is keen to encourage students to view higher education as a viable pathway, and increase student academic confidence by enabling them to develop their opinions on complex issues.

Molly Gazzard is an A-level student at Christ the King Sixth-Form College. She studies philosophy, psychology and sociology. She aims to go on to study applied theatre at degree level, using different institutions and members of society, such as those who encounter health inequalities, in application to her performance work.

Esma Yaman is an A-level student at Christ the King Sixth-form College studying sociology, economics and law, and aspiring to study economics and law at university. She has also achieved the Youth Award in Health Economics at King's College London.

Angela Murugesu is an A-level student at Christ the King Sixth-Form College.

Stephani Hatch is a reader in sociology and epidemiology at the Institute of Psychiatry, Psychology and Neuroscience, KCL. She coordinates the Health Inequalities Research Network (HERON), a public engagement network (currently funded by the Wellcome Trust) that promotes collaborative community approaches to knowledge dissemination and youth outreach.

\section{References}

Banks, S., Armstrong, A., Carter, K., Graham, H., Hayward, P., Henry, A., Holland, T., Holmes, C., Lee, A., McNulty, A., Moore, N., Nayling, N., Sotkoe, A. and Strachan, A. (2013) 'Everyday ethics in community-based participatory research'. Contemporary Social Science, 8 (3), 263-77.

Berg Powers, C. and Allaman, E. (2013) How Participatory Action Research Can Promote Social Change and Help Youth Development (Research Publication No. 2013-10). Cambridge, MA: Berkman Center for Internet and Society. 
Berlant, L. (2006) 'Cruel optimism'. Differences: A Journal of Feminist Cultural Studies, 17 (3), 20-36.

Brydon-Miller, M. and Maguire, P. (2009) 'Participatory action research: Contributions to the development of practitioner inquiry in education'. Educational Action Research, 17 (1), 79-93.

Cahill, C., Rios-Moore, I. and Threatts, T. (2008) 'Different eyes/open eyes: Community-based participatory action research'. In Cammarota, J. and Fine, M. (eds) Revolutionizing Education: Youth participatory action research in motion. New York: Routledge, 89-124.

Cammarota, J. and Fine, M. (eds) (2008) Revolutionizing Education: Youth participatory action research in motion. New York: Routledge.

Chowdry, H., Crawford, C., Dearden, L., Goodman, A. and Vignoles, A. (2013) 'Widening participation in higher education: Analysis using linked administrative data'. Journal of the Royal Statistical Society: Series A (Statistics in Society), 176 (2), 431-57.

Christ the King College (n.d.) 'Christ the King College Pupil Premium statement 2016-2017 review and Pupil Premium statement 2017-2018 actions'. Online. https://tinyurl.com/yajqsahd (accessed 4 November 2018).

Church, E. and Kerrigan, M. (2011) "[Aimhigher] Makes You Realise What You Can Actually Accomplish": A longitudinal study of Aimhigher Nottingham City and Nottinghamshire learners. Nottingham: Aimhigher. Online. https://tinyurl.com/y9y2g8qt (accessed 4 November 2018).

Cook-Sather, A. (2002) 'Authorizing students' perspectives: Toward trust, dialogue, and change in education'. Educational Researcher, 31 (4), 3-14.

Cook-Sather, A. (2006) 'Sound, presence, and power: "Student voice" in educational research and reform'. Curriculum Inquiry, 36 (4), 359-90.

Fereday, J. and Muir-Cochrane, E. (2006) 'Demonstrating rigor using thematic analysis: A hybrid approach of inductive and deductive coding and theme development'. International Journal of Qualitative Methods, 5 (1), 80-92.

Fox, M., Mediratta, K., Ruglis, J., Stoudt, B., Shah, S. and Fine, M. (2010) 'Critical youth engagement: Participatory action research and organizing'. In Sherrod, L.R., Torney-Purta, J. and Flanagan, C.A. (eds) Handbook of Research on Civic Engagement in Youth. Hoboken, NJ: Wiley, 621-50.

Hannon, C., Faas, D. and O'Sullivan, K. (2017) 'Widening the educational capabilities of socio-economically disadvantaged students through a model of social and cultural capital development'. British Educational Research Journal, 43 (6), 1225-45.

Harrison, N., Davies, S., Harris, R. and Waller, R. (2018) 'Access, participation and capabilities: Theorising the contribution of university bursaries to students' well-being, flourishing and success'. Cambridge Journal of Education, 1-19. Online. https://tinyurl.com/y8k6ycmm (accessed 4 November 2018).

Harrison, N. and Hatt, S. (2012) 'Expensive and failing? The role of student bursaries in widening participation and fair access in England'. Studies in Higher Education, 37 (6), 695-712.

Hatch, S.L., Frissa, S., Verdecchia, M., Stewart, R., Fear, N.T., Reichenberg, A., Morgan, C., Kankulu, B., Clark, J., Gazard, B., Medcalf, R. and Hotopf, M. (2011) 'Identifying socio-demographic and socioeconomic determinants of health inequalities in a diverse London community: The South East London Community Health (SELCoH) study'. BMC Public Health, 11, Article 861, 1-17. Online. https://tinyurl.com/y7mydyon (accessed 4 November 2018).

Hatch, S.L., Gazard, B., Williams, D.R., Frissa, S., Goodwin, L., SELCoH Study Team and Hotopf M. (2016) 'Discrimination and common mental disorder among migrant and ethnic groups: Findings from a South East London Community sample'. Social Psychiatry and Psychiatric Epidemiology, 51 (5), 689-701.

Heaton, J., Day, J. and Britten, N. (2016) 'Collaborative research and the co-production of knowledge for practice: An illustrative case study'. Implementation Science, 11, Article 20, 1-10. Online. https://tinyurl.com/y9hthsz5 (accessed 4 November 2018).

Kilburn, D., Nind, M. and Wiles, R. (2014) 'Learning as researchers and teachers: The development of a pedagogical culture for social science research methods?'. British Journal of Educational Studies, 62 (2), 191-207.

Kirshner, B., Pozzoboni, K. and Jones, H. (2011) 'Learning how to manage bias: A case study of youth participatory action research'. Applied Developmental Science, 15 (3), 140-55.

Michels, B.I. and Eijkelhof, H.M.C. (2018) 'High-school students engaging with researchers within a pre-university programme: Motivations and experiences'. Research for All, 2 (1), 43-61.

Ofsted (2010) Christ the King Sixth Form College: Inspection report. Online. https://files.api.ofsted. gov.uk/v1/file/973661 (accessed 3 December 2018). 
Ostrom, E. (1996) 'Crossing the great divide: Coproduction, synergy, and development'. World Development, 24 (6), 1073-87.

REACH (Resilience, Ethnicity, and Adolescent Mental Health) (n.d) 'The REACH Study'. Online. www.thereachstudy.com (accessed 7 October 2018).

Rodríguez, L.F. and Brown, T.M. (2009) 'From voice to agency: Guiding principles for participatory action research with youth'. New Directions for Youth Development, 123, 19-34.

Simmons, C., Graham, A. and Thomas, N. (2015) 'Imagining an ideal school for wellbeing: Locating student voice'. Journal of Educational Change, 16 (2), 129-44.

Vignoles, A. and Murray, N. (2016) 'Widening participation in higher education'. Education Sciences, 6 (2), Article 13, 1-4. Online. www.mdpi.com/2227-7102/6/2/13 (accessed 23 October 2018). 